\title{
Neonatal morbi-mortality in very low birth weight in Europe: The Portuguese experience
}

\author{
TERESA TOMÉ ${ }^{1}$, H. GUIMARÃES ${ }^{2}$, A. BETTENCOURT ${ }^{1}$, \& J. C. PEIXOTO ${ }^{3}$ \\ ${ }^{1}$ Maternidade Dr. Alfredo da Costa, Lisbon, Portugal, ${ }^{2}$ São foão Hospital and Faculty of Medicine of Porto University, Porto, \\ Portugal, and ${ }^{3}$ Portuguese National Network of VLBW Infants, Portugal
}

(Received 15 fune 2009; revised 16 Fuly 2009; accepted 2 August 2009)

\begin{abstract}
The aim of this study was to access evolution in care of very low birth weight (VLBW) infants after the implementation of a regionalization policy in Portugal. The data of the National Portuguese Network of VLBW infants are analyzed concerning mortality, morbidity, and quality of regionalization. A total of 12,826 VLBW infants born from 1 January 1994 to 31 December 2008 were enrolled, with a prevalence of $0.66 \%-0.99 \%$ of all live born. The global mortality was $11 \%$. The major improvement in survival is in the babies more than $1000 \mathrm{~g}$. Since 2004 , the threshold of viability is 25 weeks, but the intact survival is around 28 weeks. In the last 10 years with more efficient regionalization more VLBW babies are born in the right place. The improvement in neonatal mortality rate was determinant in the good evolution of perinatal and infant mortalities. After reinforcement of regionalization policies, we found improvements in mortality for VLBW infants. The aims of regionalization were achieved. The reform of perinatal care in Portugal is an example of how a good diagnosis and adequate proposals combined with a strong political will is crucial for changing.
\end{abstract}

Keywords: Child mortality, perinatal mortality, regionalization policy

\section{Introduction}

The perinatal and the childhood indicators are important factors of assessment of a developed society. The quality of care provided to pregnant women, to newborn infants and particularly to preterm babies is an unquestionable assessment parameter of such development.

The first records in Portugal about child mortality in Porto are from 1893 and were published in 1908. In 1893 , and up to 1907 , the child mortality rate was of 200 deaths for thousand births, coming down to nearly 150 deaths for thousand births in the years 1910-1930, to 77.5 in 1960, 24.3 in 1980, 10.9 in 1990, 5.5 in 2000 and 3.5 in 2005 (Table I).

In the European Union context, Portugal recorded, in 1985, the highest child mortality rate $(17.8 / 1000)$ of all European Union countries. In that year, the European average was of 9.5/1000.

In 1911 neonatal mortality in the first 15 days of life was of $185 / 1000$.
Between 1990 and 2005, the neonatal and postnatal mortality rates came significantly down in Portugal. The neonatal mortality rate went from $6.9 / 1000$ in 1990 to $2.2 / 1000$ in 2005 , corresponding to a lowering of $68 \%$.In 2008 the neonatal mortality was $2.1 / 1000$.

From 2001 onwards, Portugal no longer occupied the last place in communitarian countries and in 2005 Portugal occupied the 5th place on the underfive infant mortality rate.

The growth of Neonatology occurred fundamentally on the decade of 60 of the 20th century. In the decade of 70 , the tradition of medical careers started in the University Hospitals and in the decade of 80 , came the Neonatology Units integrated in Services of Pediatrics.

The creation of the National Committee for Maternal and Child Healthcare and a Child and Maternal Hospital Healthcare Referral Network.

In 1989, the National Committee for Maternal and Child Healthcare and a Child and Maternal

Correspondence: Teresa Tomé, President of Portuguese Neonatal Society, Maternidade Dr. Alfredo da Costa, Department of Neonatology, Rua Viriato, 1069089, Lisboa, Portugal. Tel: +3512131840. Fax: +351213184029. E-mail: teresatome@netcabo.pt 
Hospital Healthcare Referral Network were created and some decisions were taken: (1) Maternities with less than 1500 deliveries per year should were closed; (2) Hospitals were classified as Perinatal Care Hospitals (Level II) and Differentiated Perinatal Care Hospitals (Level III); (3) Functional Coordinating Units (connecting the Hospitals to the Primary Healthcare Centres were created; (4) The post graduation of Paediatricians in Neonatology originated the creation of Cycles of Special Studies on Neonatology; (5) The recognition that the best transport for the 'newborn' was the mother's womb (transport in utero). When necessary a transport specifically designed for newborns (Paediatricians and Nurses trained on neonatal care) integrated in the National Institute of Medical Emergencies (INEM) was created.

The creation of the INEM, would enable the functioning of a transport system for the newborn in risk in the urban centres of Porto, Coimbra, and Lisbon and promotes the intercommunication between institutions.

As we know the transport of preterm newborns influences the mortality rate. The maternal womb was been promoted for a long time as the optimal transport and is so. Our data show that the neonatal mortality decreased about $40 \%$ if babies are transported in-utero.

Approximately $30 \%$ of the very low birth weight (VLBW) babies treated in Level III hospitals are subsequently transferred to the Level II hospitals of the residence area for continuity of care before hospital discharge.

When we compared the evolution in 10 years regarding the regionalization, we saw that more

Table I. Place of birth - evolution in 10 years.

\begin{tabular}{|c|c|c|c|c|}
\hline & & 1996 & 2005 & \\
\hline \multirow[t]{2}{*}{ In utero transport } & $n$ & 176 & 374 & \\
\hline & $\%$ & 21 & 37 & $p<0.0001$ \\
\hline \multirow[t]{2}{*}{ Birth in level III } & $n$ & 678 & 920 & \\
\hline & $\%$ & 82 & 92 & $p<0.0001$ \\
\hline \multirow[t]{2}{*}{ Neonatal transport } & $n$ & 124 & 79 & \\
\hline & $\%$ & 15 & 8 & $p<0.0001$ \\
\hline \multirow[t]{2}{*}{ In born } & $n$ & 706 & 921 & \\
\hline & $\%$ & 85 & 92 & $p<0.0001$ \\
\hline
\end{tabular}

babies born in the right place and more babies are transported in utero (Table II).

Nowadays the natality in Portugal, with about 10 millions inhabitants, is about $100.000(40,000$ in the North, 20,000 in the Centre, and 40,000 in the South) births per year and more than $10 \%$ of these babies were born in the 25 private hospitals of the country. There are 40 public hospitals being 22 Level III and 18 Level II.

Since January 1993 and belonging to the Portuguese Neonatal Society, there is a national registry of VLBW infants (birth weight $<1500 \mathrm{~g}$ ), that has allowed to analyze the assistance conditions in the country, to identify problems and to look for solutions.

The VLBW infants, despite being a minority in the total group of living births - about $1 \%$ - are a representative fraction of the country's perinatal problems, accountable for nearly $50 \%$ of neonatal deaths and more than one third of infant mortality; moreover, a significant part of these future citizens will have sequelae.

Looking to prenatal care, in this $<1500 \mathrm{~g}$ babies group, the rate of pregnancies with no follow-up was $12 \%$ and the prevalence of mothers with drug problems was $2 \%$.

In last decades, with the introduction of assisted reproduction techniques, the number of multiple pregnancies has significantly increased. Portuguese prevalence of VLBW multiples is about $25 \%$.

The evolution of mortality per birth weight at 3 months of life, from 1996 to 2005, is shown in Figure 1.

In babies with $\mathrm{BW}>1000 \mathrm{~g}$, the survival increased from $87.7 \%$ to $96.1 \%$ and in those with $\mathrm{BW}<1000 \mathrm{~g}$ the survival increased from $45.3 \%$ to $70 \%$.

In Portugal, the limit of viability (more than 50\% of survivors) was, in 2005, 25 weeks and $600 \mathrm{~g}$, and the limit of survival without damage (more than 50\% of survivors without problems at discharge or at 3 months of life) was 27 weeks of GA and $800 \mathrm{~g}$ of birth weight.

Concerning the causes of death in these VLBW infants, the most frequent was infection (19.7\%). Intraventricular hemorrhage stands on second place $(15.4 \%)$. Congenital anomalies represent $11 \%$ and the immaturity $9.7 \%$.

Table II. Infant, perinatal, neonatal, and foetal mortalities since 1995 to 2008.

\begin{tabular}{|c|c|c|c|c|c|c|c|c|c|c|c|c|}
\hline & \multicolumn{12}{|c|}{ Years } \\
\hline & 1995 & 1997 & 1999 & 2000 & 2001 & 2002 & 2003 & 2004 & 2005 & 2006 & 2007 & 2008 \\
\hline Infant mortality (\%) & 7.4 & 6.4 & 5.6 & 5.5 & 5.0 & 5.0 & 4.1 & 3.8 & 3.5 & 3.3 & 3.4 & 3.3 \\
\hline Perinatal mortality (\%) & 9.0 & 7.2 & 6.4 & 6.2 & 5.6 & 6.0 & 5.1 & 4.4 & 4.3 & 4.6 & 4.3 & 4 \\
\hline Neonatal mortality (\%) & 4.7 & 4.1 & 3.6 & 3.4 & 2.9 & 3.4 & 2.7 & 2.6 & 2.2 & 2.8 & 2 & 2.1 \\
\hline Fetal mortality (\%) & 5.5 & 4.4 & 3.7 & 3.7 & 3.4 & 3.4 & 3.1 & 2.7 & 2.8 & 3.1 & 3.6 & 3.2 \\
\hline
\end{tabular}




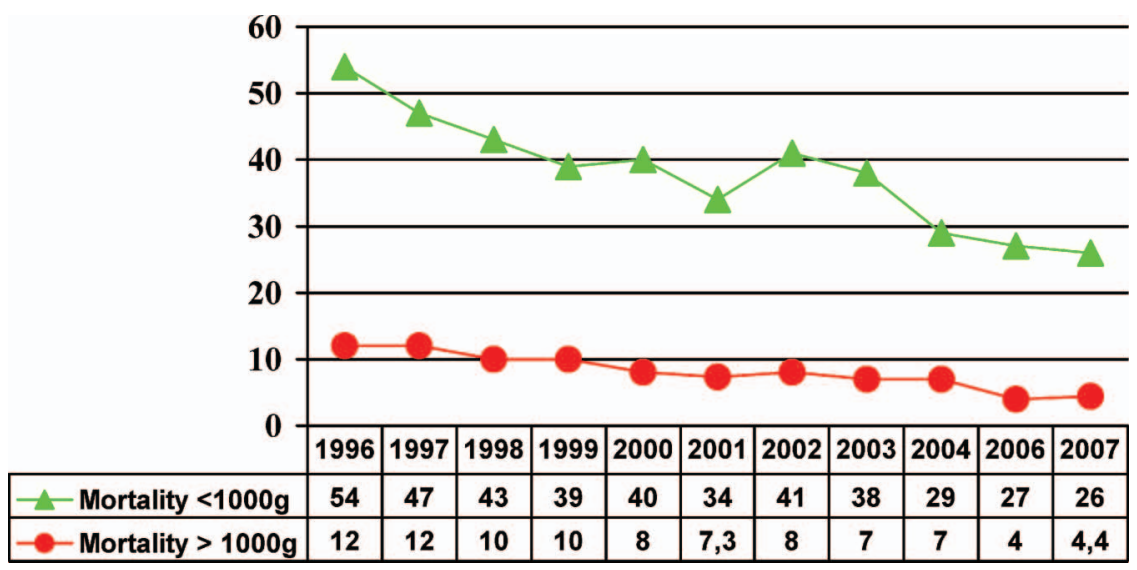

Figure 1. Mortality for infants $<1500 \mathrm{~g}$ at 3 months.

Most infants with more than 27 weeks survive without an increase of the rate of sequelae. However, between 23 and 25 weeks and $\mathrm{BW}<700 \mathrm{~g}$ the rate of sequelae of varying severity was $50 \%$.

Approximately $10 \%$ of these preterm babies will survive with complex problems, requiring multidisciplinary intervention, social and economical support.

The success of this work that was based on the improvement of social and economic conditions of the population but also in the motivation, professionalism, co-operation, training of national neonatologists, on the free and voluntary adherence of the Hospitals. The accomplishment of objectives with the available resources, the extension to all Level II hospitals, the annual discussion of results, the creation of working groups, but fundamentally, on the will to learn and to serve a excessively fragile population.

Such work allowed to perform a study 'VLBW infants in Portugal - National Multicenter Study 1996-2000', winner of the Bial Award for Clinical Medicine in 2002.

\section{Conclusion}

In conclusion, the increasing qualification of obstetric assistance to pregnant women and to labour, the creation of INEM and of the National Committee for Maternal and Child Healthcare, and the improvement of social and economic conditions of the population were decisive factors of the positive results concerning the indicators of perinatal healthcare in Portugal.

After reinforcement of regionalization policies, we found improvements in mortality for VLBW infants, a good indicator of quality in perinatal healthcare. The aims of regionalization were achieved. The reform of perinatal care in Portugal is an example of how a good diagnosis and adequate proposals combined with a strong political will is crucial for changing.

Declaration of interest: The authors report no conflicts of interest. The authors alone are responsible for the content and writing of the paper.

\section{References}

1. Garret AA. Mortalidade infantil. Dissertação de concurso. Porto: FMUP; 1908

2. Barreto A. A Situação Social em Portugal 1960-1999. Indicadores sociais em Portugal e na União Europeia. Eurostat; 2000.

3. VLBW infants in Portugal. Bial Award of Clinical Medicine 2002. Porto: National Multicenter Study; 2002.

4. Ferraz AR, Guimarães H. O ensino da Pediatria na Escola médica do Porto. Porto: FMUP; 2004. 
Copyright of Journal of Maternal-Fetal \& Neonatal Medicine is the property of Taylor \& Francis Ltd and its content may not be copied or emailed to multiple sites or posted to a listserv without the copyright holder's express written permission. However, users may print, download, or email articles for individual use. 